\title{
Long-range transport of Asian dust and air pollutants to Taiwan: observed evidence and model simulation
}

\author{
C.-Y. Lin $^{1}$, Z. Wang ${ }^{2}$, W.-N. Chen ${ }^{1}$, S.-Y. Chang ${ }^{1}$, C. C. K. Chou ${ }^{1}$, N. Sugimoto ${ }^{3}$, and X. Zhao ${ }^{2}$ \\ ${ }^{1}$ Research Center for Environmental Changes, Academia Sinica, Taipei 115, Taiwan \\ ${ }^{2}$ Institute of Atmospheric Physics, Chinese Academy of Sciences, Beijing, China \\ ${ }^{3}$ National Institute for Environmental Studies, Onogawa, Tsukuba, Japan \\ Received: 27 September 2006 - Published in Atmos. Chem. Phys. Discuss.: 12 October 2006 \\ Revised: 13 December 2006 - Accepted: 17 January 2007 - Published: 24 January 2007
}

\begin{abstract}
Long-range transport of Asian dust and air pollutants are major environmental concerns of Taiwan during the winter monsoon season when northeasterly winds prevail following passages of cold fronts. Based on hourly measurements of Taiwan Environmental Protection Administration (TEPA) air quality monitoring stations, Lidar and insitu IC, a significant long-range transport dust and air pollutants event on 18 March 2005 has been identified. During this episode, drastically elevated concentrations of $\mathrm{PM}_{10}, \mathrm{CO}$ and $\mathrm{SO}_{2}$ along with the strong northeasterly on 18 March were observed over background Wanli station, with peaks of about $170 \mu \mathrm{gm}^{-3}, 1.0 \mathrm{ppm}$ and $14 \mathrm{ppb}$, respectively. We have found that air masses of air pollutants and Asian dust are transported separately. Although the mixing takes place on the way to Taiwan, it mixes slightly when they arrived in Taiwan. The major component of the first $\mathrm{PM}_{10}$ peak were air pollutants, evidenced by the consistent peaks of $\mathrm{SO}_{4}^{2-}$ and $\mathrm{NO}_{3}^{-}$measured by in-situ IC, while no significant depolarization was measured by Lidar. In contrast, the evident non-spherical particles and hourly $\mathrm{PM}_{10}$ concentration consistently varied with $\mathrm{Ca}^{2+}$ indicating that mineral dust was the major component of the second peak. Trajectory analysis showed that these two peaks come from quite different sources areas. The air masses of the first peak mainly come from anthropogenic area and transport in the low boundary layer $(<1500 \mathrm{~m})$ while the masses of the second peak originate from high altitude $(>4000 \mathrm{~m}$ ) of desert areas. Numerical results showed significant agreement of temporal and vertical variation of aerosol concentration with observations. The phenomena of split air parcels between air pollutants and Asian dust transported to Taiwan are strongly associated with the transport paths and stable and dry atmospheric boundary conditions.
\end{abstract}

Correspondence to: C.-Y. Lin

(yao435@ rcec.sinica.edu.tw)

\section{Introduction}

The topic of long-range transport of desert dust during late winter and spring in East Asia is well documented (e.g. Shaw, 1980; Duce et al., 1980; Prospero et al., 1989; Murayama et al., 2001). Many researchers have noted the effect of the high aerosol load caused by frequent Asian dust outbreak, such as reduced visibility, biogeochemical cycles, and the atmospheric radiation budget (e.g. Uematsu et al., 1983; Li et al., 1996; Chun et al., 2001; Sokolik and Toon,1996; IPCC, 2001; Seinfeld et al., 2004).

Except for the dust storms, anthropogenic emissions over East Asia also received much attention recently. Along with economic growth, East Asia has been a region of rapidly increasing emissions of air pollutants in the past decades. In the winter and spring, Taiwan and vicinity is often under the influence of northeasterly winter monsoon winds originating in central Asia. The winter monsoon not only brings cold air, but can also transport air pollutants and dust over a long distance to Taiwan and even to the northwestern Pacific area (Arimoto et al., 1996; Uno et al., 2001; Uematsu et al., 2003; Takemural et al., 2002). This is evident from satellite observations such as AVHRR, MODIS, and SEAWIFS (Husar et al., 2001; Nakajima et al., 2003), that show a pronounced enhancement of aerosol optical depth during winter and spring over the western North Pacific as a result of Asian continental outflow. Takemura et al. (2002) pointed out that 50\% of the total optical thickness around Japan is due to anthropogenic aerosols during the strong Asian dust events. Based on the qualitative analysis from background stations of Taiwan Environmental Protection Administration (TEPA), Lin et al. (2004) presumed the contribution of long-range transport to $\mathrm{PM}_{10}$ abundance in northern Taiwan to range from $50 \%$ to $70 \%$ during the northeasterly monsoon. Recently, Lin et al. (2005) estimated that the long-range transport of particulate pollutants in northern and eastern Taiwan contributes to $\mathrm{PM}_{10}, \mathrm{CO}$ and $\mathrm{SO}_{2}$ concentrations of about $30 \mu \mathrm{g} / \mathrm{m}^{3}$, $230 \mathrm{ppb}$ and $0.5 \mathrm{ppb}$, respectively.

Published by Copernicus GmbH on behalf of the European Geosciences Union. 
Prospero et al. (2003), in a study of aerosols distributions at Midway Island during 1981-2000, found that pollutants such as sulfate and nitrate ions in the aerosols increased concurrently with mineral dust in spring and winter. Over a long period, the anthropogenic pollutant increases along with mineral dust in the spring. Uno et al. (2001) illustrated a long-range transported case by numerical model and showed that mineral dust and anthropogenic tracer are simultaneously transported to the central Pacific Ocean. However, in our study, the hourly data analysis taken from TEPA air quality monitoring stations showed that most of the dust storm cases usually do not pick up significant air pollutants, or randomly carried pollutants during long-range transport of dust storm episode (Lin et al., 2004). Also, Uematsu et al. (2002) pointed out that Asian dusts are occasionally capable of transporting mineral and anthropogenic particles to the western North Pacific. Matsumoto et al. (2003) found out anthropogenic fine particles containing abundant nss- $\mathrm{SO}_{4}^{2-}$ appeared first and were then followed by large mineral particles that had absorbed $\mathrm{NO}_{3}^{-}$. This phenomena is different from that proposed by Prospero et al. (2003) and Uno et al. (2001). The consistent feature found by Prospero et al. (2003) were based on seasonal variations, while the lack of correlation observed at TEPA stations were at time scale of about an hour or less (Lin et al., 2004). Furthermore, Taiwan and Japan lie just off the major emission sources region, so it might take some time to admix the different air masses including various types of aerosols (Uematsu et al., 2002). It is presumed that whether air pollutants are consistently carried by dust storms or not is strongly associated with the paths of the air mass transport and boundary structures. Therefore, the processes of long-range transport are complex and need further discussion.

K. Matsumoto et al. (2003) showed that the transport patterns of the polluted air masses from the east Asian continent to the northern regions of the northwestern Pacific are often different from those to southern regions. Asian dust transport mainly between 30 40 N (Zhao et al., 2003; Satake et al., 2004) while sulfate and carbon is between $25 \sim 45 \mathrm{~N}$ (Satake et al., 2004). More importantly, this is the first time observed and discussed the separately transport phenomenon between Asian dust and air pollutants over low latitude (less than $25 \mathrm{~N}$ ) location such as Taiwan. This report completes the picture in the region.

In this paper, we investigate a separately transport case of Asian dust and air pollutants air masses to Taiwan. In this study, measurement of TEPA ground stations, In-situ IC and Lidar are used to analyze the episode. The Nested Air Quality Prediction Model System (NAQPMS) is employed to study the process of the long-range transport of dust and air pollutants to Taiwan.

\section{Data source and instruments}

Measurements of hourly $\mathrm{PM}_{10}$ and other pollutants were taken from TEPA air quality monitoring stations. Meteorological parameters, i.e. surface temperature, wind direction and speed, rainfall, and atmospheric concentrations of $\mathrm{PM}_{10}$, $\mathrm{NO}_{\mathrm{x}}, \mathrm{CO}$, and $\mathrm{SO}_{2}$ observed at a coastal background station and a mountain station in northern Taiwan were used in this study. The coastal background station Wanli (Fig. 1) is upwind from the frontal passage and thus ideal for observing the effect of frontal passages on distribution of dust and air pollutants. Measurements at Yangming mountain station (altitude $826 \mathrm{~m}$ ) at a national park in northern Taiwan turn out to be very valuable also because it is relatively clean and provides information on vertical distribution of trace species.

The aerosol composition was analyzed by an in-situ IC system (Chang et al., 2006), which provides concentrations of water-soluble ions $\mathrm{Cl}^{-}, \mathrm{NO}_{2}^{-}, \mathrm{NO}_{3}^{-}, \mathrm{SO}_{4}^{2-}, \mathrm{Na}^{+}, \mathrm{NH}_{4}^{+}$, $\mathrm{K}^{+}$, and $\mathrm{Ca}^{2+}$. The location of the sampling site $(25 \mathrm{~N}$, 121.32 E, Fig. 1) is at the weather observatory of the National Taiwan University (NTU), which is located in the southwestern part of the Taipei Basin. The in-situ IC system consisted of gas removal denuders, aerosol collecting device, and ion chromatograph (Model ICS-90, Dionex Corp., Sunnyvale, CA, YSA), and was attached to the bypass flow line of the TEOM monitor to measure the water-soluble inorganic ions $\mathrm{PM}_{2.5}$ during spring of 2005 throughout at 15-min intervals $\left(\mathrm{PM}_{10}\right.$ is not available in this study). At the same location, a Lidar system (hereafter referred to as RCEC/ASNTU Lidar) was set up from 2004. RCEC/ASNTU Lidar is a dualwavelength Raman and Depolarization Lidar system (manufactured by Zenon SA, Greece). The lidar system employs the second and third harmonics of Nd-YAG laser at $532 \mathrm{~nm}$ and $355 \mathrm{~nm}$. This system is operated on a $24 \mathrm{~h}$ basis to probe the atmosphere at elevations ranging between $0.3 \mathrm{~km}$ and $8 \mathrm{~km}$. More details are shown in Table 1. Meanwhile, Lidars performed by National Institute for Environmental Studies (NIES) located in China and Japan were also employed to compare the model results.

\section{Model description}

The NAQPMS is a fully modularized three-dimensional system with various options for representing the physical and chemical processes describing regional and urban atmosphere pollution (Wang et al., 2000, 2002). It consists of two parts, a regional chemical transport model and the FifthGeneration PSU/NCAR Mesoscale Modeling System, MM5 (Grell et al., 1995), which is used to generate meteorological fields. The initial and boundary conditions for MM5 are obtained from NCAR/NCEP $2.5^{\circ} \times 2.5^{\circ}$ reanalysis data sets at 6-hour intervals. The model can employ flexible horizontal grid resolution with multiple level nested grids for regional applications and urban scale simulations. Even NAQPMS 


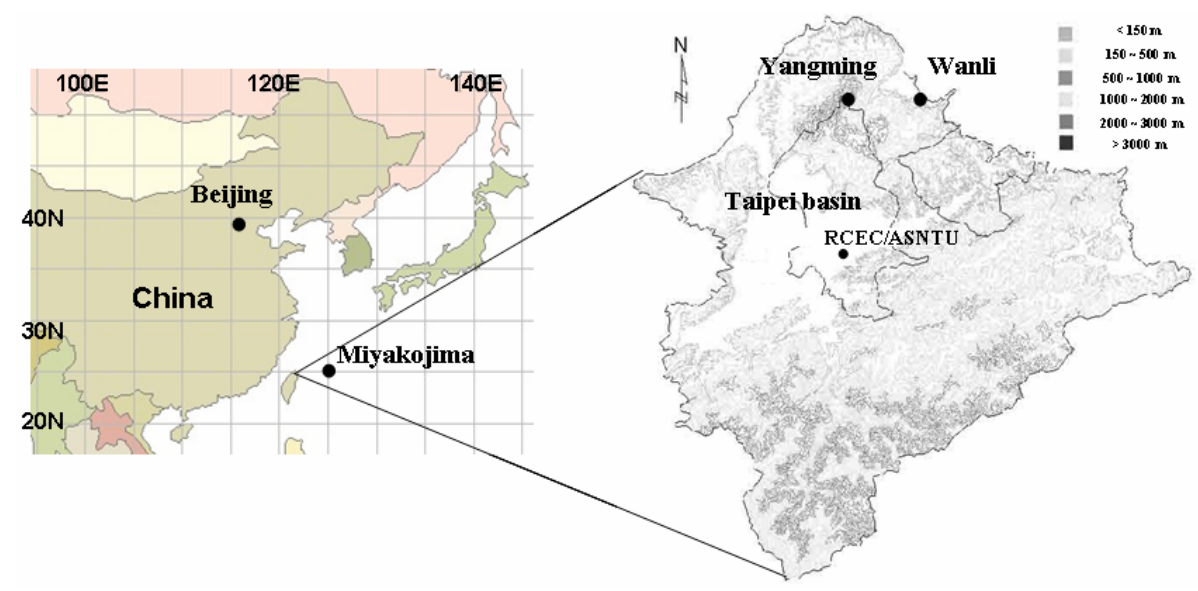

Fig. 1. Locations of Lidar sites for RCEC/ASNTU and Miyakojima and the TEPA background stations Yangming and Wanli.

Table 1. RCEC/ASNTU lidar characteristics.

\begin{tabular}{ll}
\hline Laser & Nd:YAG (Big-Sky CFR-400) \\
Wavelength & $532 / 355 \mathrm{~nm}$ \\
Pulse energy & $65 / 60 \mathrm{~mJ}$ \\
Repetition rate & $20 \mathrm{~Hz}$ \\
Transient Recorder & $12 \mathrm{bits} \mathrm{A/D} \mathrm{converter} \mathrm{at} 20 \mathrm{MHz}$ and $250 \mathrm{MHz}$ photon counting (Licel TR20-40) \\
Height Resolution & $7.5 \mathrm{~m}$ \\
Telescope & diameter $40 \mathrm{~cm}$, focal length $160 \mathrm{~cm}$ \\
Channels & $532 \mathrm{~nm}($ depolization), $355 \mathrm{~nm}$, and $387 \mathrm{~nm}$ (nighttime only) \\
\hline
\end{tabular}

model can employ multiple level nested grid only one domain $(91 \times 73$ grid boxes in the east-west and south-north directions) was employed with $81 \mathrm{~km}$ resolution in this study. Vertically, the model divides the troposphere from surface to $100 \mathrm{hPa}$ into 20 layers using variable-spaced sigma coordinates and the thickness of the surface layer is about $70 \mathrm{~m}$.

A modified dust deflation module is embedded in NAQPMS. The detail methodology for dust emission was described by Wang et al. (2002). In this application, soil dust emission intensity is modified with the vegetation fraction percentages and soil categories based on the approach of Wang et al. (2000):

$$
Q_{i}=C_{1} \times u *^{2} \times\left(1-u_{0}^{*} / u^{*}\right) \times W \times R_{i} \times \sum C_{j} f_{j},
$$

where $u^{*}$ and $u^{*}{ }_{0}$ are the fraction and threshold friction velocities and $C_{1}$ is an empirical constant set as $2.9 \times 10^{-11}(\mathrm{Hu}$ and $\mathrm{Qu}, 1997) ; C_{j}$ is the weighting factor of dust loading for $j$ type of vegetation that is obtained from the U.S. Geological Survey (USGS) data with a horizontal resolution of $10 \mathrm{~min}$; $f_{j}$ is the vegetation fraction percentage of $j$ type of vegetation in a model grid that is derived from the AVHRR data. The humidity factor $W$ is assumed to be linearly dependent on the relative humidity (Wang et al., 2000). $R_{i}$ is the fraction of the $i$-th bin of deflating dust and is obtained from the size distribution of floating dust in source area (Table 2).
The dust particle size is divided into 10 size bins from 0.43 to $42 \mu \mathrm{m}$ in diameter in terms of the eight stages of aerosol sampler, with three additional size bins above $11 \mu \mathrm{m}$ for larger particles. Table 2 lists the particle size ranges. The size distribution of dust emission is an important parameter for dust simulation. In this study, the total dust emission flux is apportioned to each size bin based on the observation of the size distribution of soil dust in Chinese source regions within and on the edge of deserts (Zhang et al., 2003; Gao et al., 2002).

The emissions of air pollutants in Asia were obtained from the East Asia inventory by Streets et al. (2003). Meanwhile, in order to evaluate the amount of long-range transport, local emissions are excluded in this study. The model domain in this study is shown in Fig. 6. This model has been successfully used to study the atmospheric trace gases and particles, such as $\mathrm{SO}_{\mathrm{x}}$, dust, $\mathrm{O}_{3}$, and acid rain over East Asia (Wang et al., 2000, 2002; Uematsu et al., 2003; Lin et al., 2007).

\section{Results}

\subsection{Observation analysis}

Figures $2 \mathrm{a}$ and $\mathrm{b}$ show the time series of the hourly meteorological parameters, $\mathrm{PM}_{10}$ and other pollutants from air 


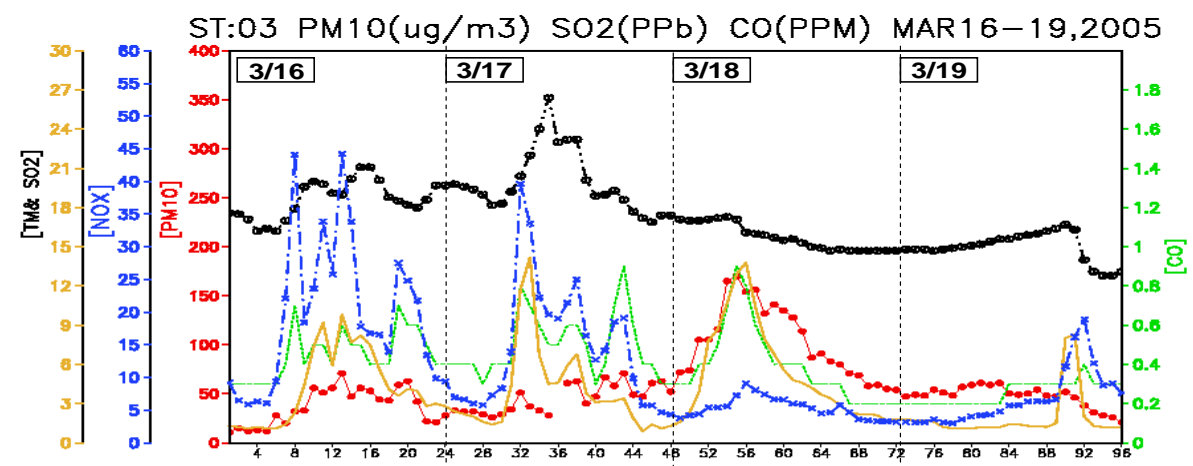

(a)
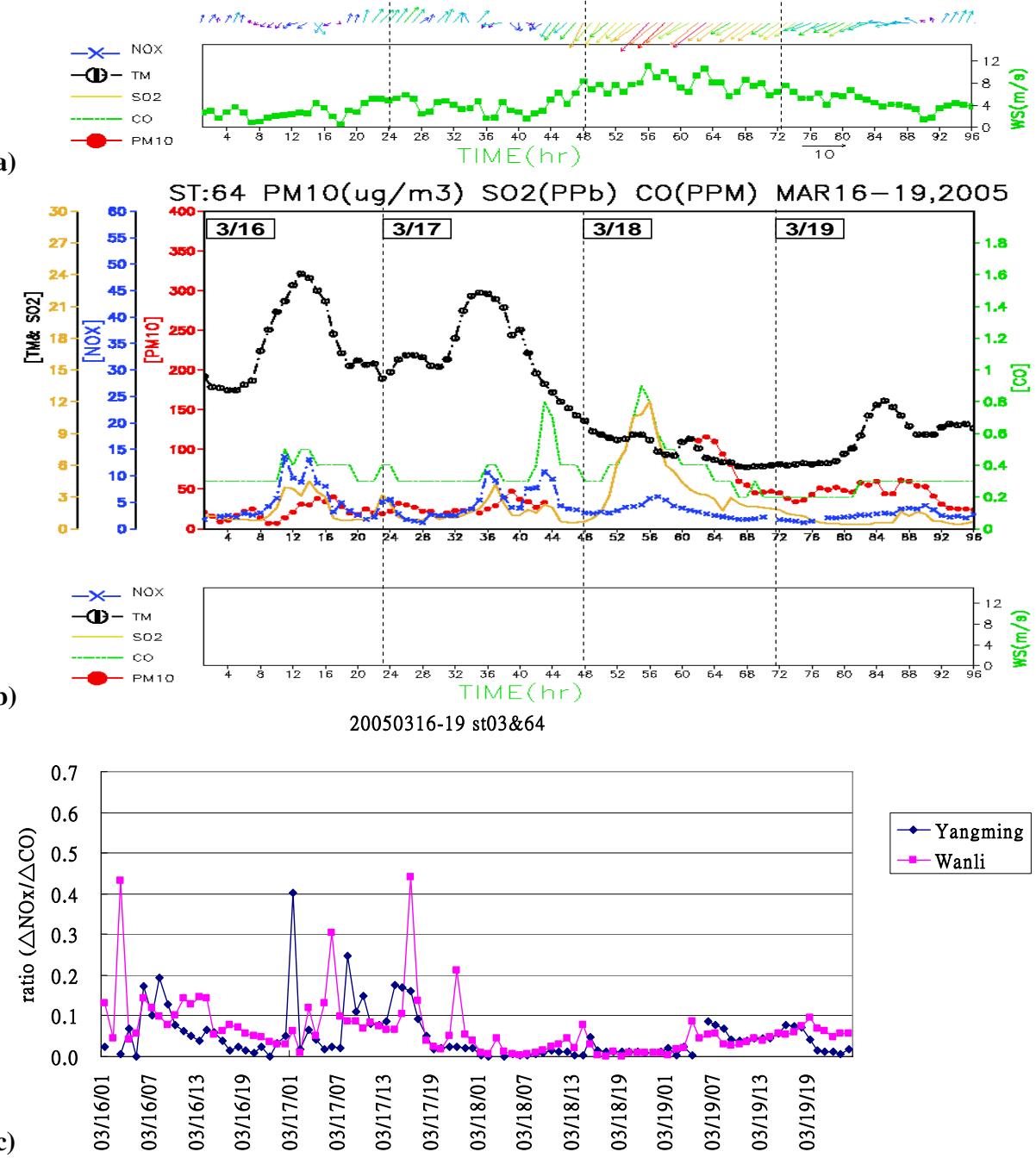

Fig. 2. The time series of hourly $\mathrm{PM}_{10}$ (red closed circles), $\mathrm{CO}$ (dashed line), $\mathrm{SO}_{2}$ (solid), $\mathrm{NO}_{\mathrm{x}}$ (cross), surface temperature (TM, open circle with vertical line), wind speed (closed square, bottom panel) are shown at (a) Wanli station (b) Yangming station ( from 01:00 LST 16 March to 24:00 LST 19 March 2005). Surface wind at Wanli station is represented by wind vector while wind field is not available at Yangming station. Data missing is between 45th and 60th for $\mathrm{PM}_{10}$ at Yangming station. (c) The time series of enhancement hourly ratio of $\left(\Delta \mathrm{NO}_{\mathrm{x}} / \Delta \mathrm{CO}\right)$ at stations Wanli and Yangming from 01:00 LST 16 March to 24:00 LST 19 March 2005. 
quality monitoring stations Wanli and Yangming. The data indicates that the cold front arrived around midnight of 17 March 2005 and that the temperature reached the minimum when the wind speed reached the maximum on 18 March 2005. Although wind speed and temperature significantly varied, no rainfall was monitored at Wanli in this case. Before the frontal passage, local pollution dominated on 16 and 17 March and showed clear diurnal variation in air pollutants. During local pollution days, daytime anthropogenic emissions at rush hour lead to the concurrent enhancement of air pollutants such as $\mathrm{NO}_{\mathrm{x}}, \mathrm{CO}$, and $\mathrm{SO}_{2}$. At night, concentrations of all pollutants drop gradually to their minima. After the cold front passed over northern Taiwan on 18 March, the surface temperature dropped to a minimum, wind speed increased to a maximum and the wind changed to northeasterly. The strong winds swept away most of the local pollutants while $\mathrm{NO}_{\mathrm{x}}$ stayed at extremely low values and showed no diurnal cycle. In this situation, local pollutants become less evident or even disappear all together. In order to further analyze whether the pollution is major contributed by local or long-range transport, we assume the average concentrations during early morning (01:00 05:00 LST) as the baseline concentration of the day. Thus, the enhancement of the concentrations of hourly incremental $\mathrm{NO}_{\mathrm{x}}$ and $\mathrm{CO}$ (i.e. $\triangle \mathrm{NOx}$ and $\Delta \mathrm{CO}$ ) could be examined. Figure $2 \mathrm{c}$ shows the enhancement ratio of short lived $(\Delta \mathrm{NOx})$ to long lived specie $(\Delta \mathrm{CO})$. The values of the enhancement ratio (i.e. $\Delta \mathrm{NOx} / \Delta \mathrm{CO}$ ) remained low at both Wanli and Yangming stations stably on 18 October and is significantly different from that identified local pollution days. It is important to note that the contributions of local emissions are quite minor on the episode day. Therefore, most of the enhancement of air pollutants can be attributed to the long-range transport.

Figure 2a shows that northeasterly winds with maximum speed of about $12 \mathrm{~m} / \mathrm{s}$ brought an air mass from the Asian continent with $\mathrm{PM}_{10}, \mathrm{CO}$, and $\mathrm{SO}_{2}$ concentrations that coincidently peaked at 07:00 LST (i.e. the 55th hour of Figs. 2a and b) on 18 March 2005 at windward Wanli station at about $170 \mu \mathrm{g} / \mathrm{m}^{3}, 1.0 \mathrm{ppm}$, and $14 \mathrm{ppb}$, respectively. Under the strong northeasterly wind (mean wind speed was $7.86 \mathrm{~m} / \mathrm{s}$ on $18 \mathrm{March}$ ), the average concentrations at Wanli station on 18 March for $\mathrm{PM}_{10}, \mathrm{CO}$, and $\mathrm{SO}_{2}$ were $103 \mu \mathrm{g} / \mathrm{m}^{3}, 390 \mathrm{ppb}$, and $5.3 \mathrm{ppb}$, respectively. By using two years' dust storm episodes, Lin et al. (2005) estimated that the average inflow concentration of $\mathrm{PM}_{10}, \mathrm{CO}$, and $\mathrm{SO}_{2}$ of dust events were $71 \pm 34 \mu \mathrm{g} / \mathrm{m}^{3}, 359 \pm 88 \mathrm{ppb}$, and $1.1 \pm 0.5 \mathrm{ppb}$, respectively. It is apparent that more than 3 times of mean $\mathrm{SO}_{2}$ concentration arrived via long distance transported over Taiwan for this case. The concentration of $\mathrm{PM}_{10}, \mathrm{CO}$, and $\mathrm{SO}_{2}$ were well correlated at the north tip of coastal station Wanli before 10:00 LST on 18 March. Although there are a few hours' $\mathrm{PM}_{10}$ data missing for Yangming station (Fig. 2b), its variation trend is similar to Wanli. Apparently, the consistent hourly variations of $\mathrm{PM}_{10}$ and air pollutants in the morning of 18 March are characteristic of the long-range trans-
Table 2. Particle size ranges and the fraction of mass size distributions (MSD) of vertical dust flux for three major desert regions of China used in this study.

\begin{tabular}{cccc}
\hline Bin & $\begin{array}{c}\text { Size Range in } \\
\text { Diameter } \mu \mathrm{m}\end{array}$ & $\begin{array}{c}\text { Middiameter } \\
\mu \mathrm{m}\end{array}$ & $\begin{array}{c}\text { the fraction of MSD } \\
(\mathrm{Ri})\end{array}$ \\
\hline 1 & $0.43-0.65$ & 0.53 & 0.03 \\
2 & $0.65-1.1$ & 0.84 & 0.04 \\
3 & $1.1-2.1$ & 1.52 & 0.07 \\
4 & $2.1-3.3$ & 2.63 & 0.1 \\
5 & $3.3-4.7$ & 3.95 & 0.12 \\
6 & $4.7-7.0$ & 5.76 & 0.15 \\
7 & $7.0-11.0$ & 8.85 & 0.18 \\
8 & $11.0-17.5$ & 14.0 & 0.11 \\
9 & $17.5-27.0$ & 21.5 & 0.09 \\
10 & $27.0-42.0$ & 34.0 & 0.11 \\
\hline
\end{tabular}

port event with a significant amount of air pollutants from the Asian continent as propounded by Lin et al. (2004). The concentration of $\mathrm{SO}_{2}(\mathrm{CO})$ dropped drastically from $14 \mathrm{ppb}$ (1.0 ppm) at 08:00 LST to $3 \mathrm{ppb}(0.3 \mathrm{ppm})$ after 16:00 LST (i.e. the 64th hour of Figs. $2 \mathrm{a}$ and b). However, $\mathrm{PM}_{10}$ concentration did not consistently drop with air pollutants but peaked at 11:00 LST on 18 March. In other words, there was a second peak at around noon as a result of the variation of hourly $\mathrm{PM}_{10}$ at Wanli station.

In order to identify the sources and to examine how transport paths affect the concentrations of air pollutants in northern Taiwan, a three-day backward trajectory analysis was preformed for this case. The analysis was computed using the HYSPLIT (Hybrid Single-Particle Lagrangian-Integrated Trajectory) model (Draxler and Hess, 1998). The backward trajectory analysis was performed for altitudes of 100 , 500 , and $1000 \mathrm{~m}$ at Wanli station in northern Taiwan. Figures $3 \mathrm{a}$ and $\mathrm{b}$ shows the 72-h backward trajectory starting from 00:00 UTC (08:00 LST) and 04:00 UTC (12:00 LST) on 18 March 2005. From the backward trajectory analysis in northern Taiwan showed that these two peaks in Fig. 2 come from quite different sources areas. For the first peak, the air parcels at $100 \mathrm{~m}, 500 \mathrm{~m}$ and $1000 \mathrm{~m}$ mostly moved in the low boundary $(<1500 \mathrm{~m})$ over industrial areas of Mainland China before traveling to Taiwan (Fig. 3a). However the second peak, the air parcels at $1000 \mathrm{~m}$ with the source of air masses originated from higher altitude $(>4000 \mathrm{~m})$ of desert areas (Fig. 3b). The atmospheric condition was considerably stable and was evident that the high pressure center measured nearly $1052 \mathrm{hpa}$ around Mongolia (Fig. 4a) on 16 March 2005. The dry atmospheric conditions and strong pressure gradient led to the occurrence of dust storms over Inner-Mongolia (Fig. 4a). Following the anticyclone outflow, Asian dust was transported to the downstream regions such as Korea, Japan and Taiwan as shown in Fig. 4b. Tracing the air masses trajectory, the sounding of Shanghai (not shown) 
(a)

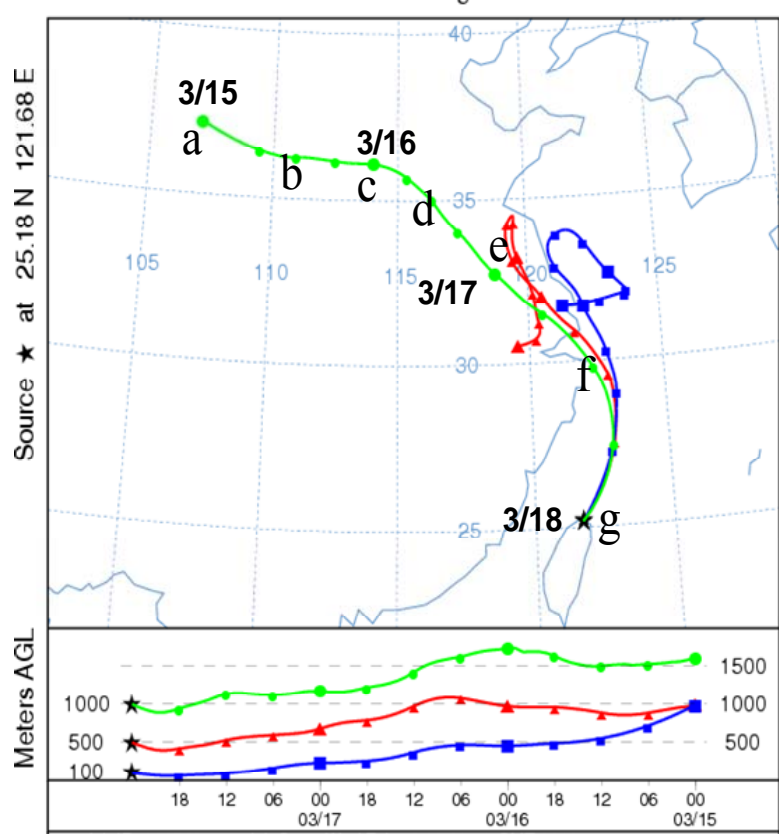

NOAA HYSPLIT MODEL Backward trajectories ending at 04 UTC 18 Mar 05

FNL Meteorological Data

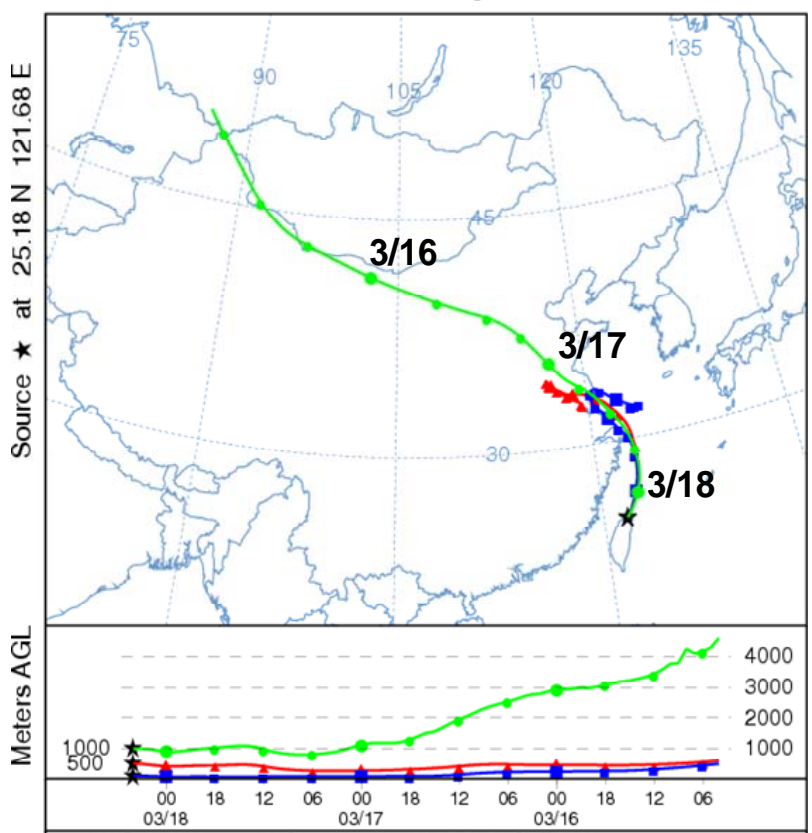

(b)

NOAA HYSPLIT MODEL

Backward trajectories ending at 00 UTC 18 Mar 05

FNL Meteorological Data

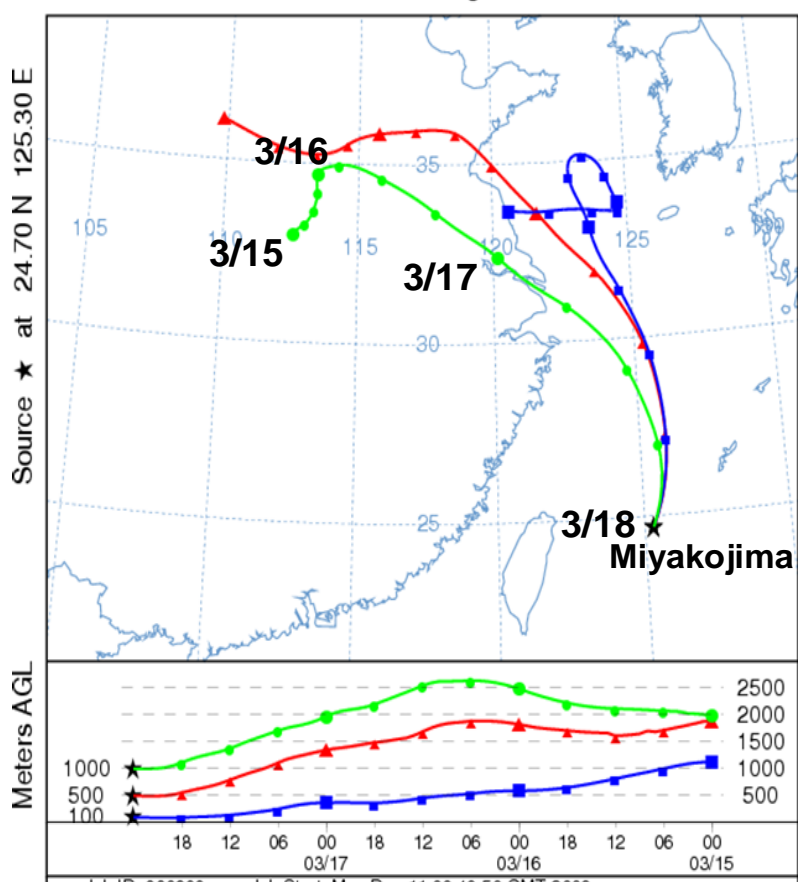

(c)

Fig. 3. Result of the HYSPLIT model 3-day backward trajectory analysis started at altitudes of 100, 500 and 1000 m at (a) 00:00 UTC (08:00 LST) at Wan-Li station in northern Taiwan. (b) 04:00 UTC(12:00 LST) at Wan-Li station in northern Taiwan (c) 00:00 UTC (08:00 LST) at Miyakojima station on 18 March 2005. The top and bottom panels display horizontal and vertical motion. Symbols denote the location of the air parcel every $6 \mathrm{~h}$. The letters a to $\mathrm{g}$ are represented the geographic locations in Fig. 7 in $\mathrm{x}$-axis. 

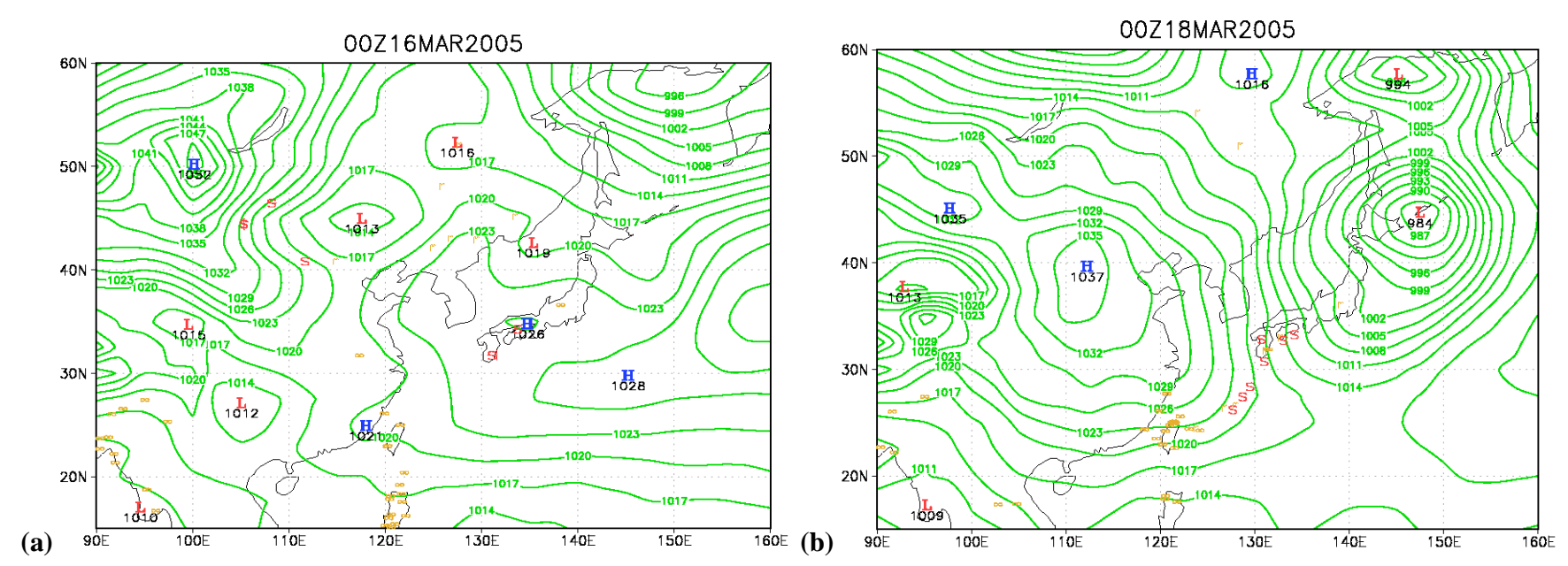

Fig. 4. Surface weather chart and dust storm report (denoted by dollar signs) at 00:00 UTC on (a) 16 March 2005 (b) 18 March 2005. Symbols of $\mathrm{H}$ and $\mathrm{L}$ show the location of major high and low pressure systems.

at 00:00 UTC on 17 March 2005 shows that the inversion layer was nearly $800 \mathrm{hpa}$ (about $2 \mathrm{~km}$ in altitude), caused by the strong subsidence of the cold high. Following the strong prevailing northeasterly flow, the sounding of Taipei (not shown) also displayed the same inversion height on 18 March 2005 , i.e. the subsidence inversion layer at nearly $2 \mathrm{~km}$. During three days of transport, the air parcels of 100 and $500 \mathrm{~m}$ are mostly at relatively low altitude (below $1000 \mathrm{~m}$ ). In other words, air masses are mostly transported in the low boundary during the transport periods. Therefore, the probability for these air parcels of picking up air pollutants over industrial areas should be relatively high.

Figure 5a shows an aerosol depolarization episode monitored by RCEC/ASNTU Lidar on 18 March 2005, during which the significant aerosol depolarization occurred from 09:00 LST to 18:00 LST. The high depolarization occurred below altitude of $1.5 \mathrm{~km}$, ranged from $5 \%$ to $10 \%$ and lasted for about $8 \mathrm{~h}$. This indicates that the non-spherical particles mainly exist after 09:00 LST on 18 March. It is important to note that mineral dust presumably reached northern Taiwan after 09:00 LST. Furthermore, the major composition of the secondary peak as a result of the hourly variation of $\mathrm{PM}_{10}$ concentration (Fig. 2a) detected at Wanli station around noon was mineral dust. To the contrary, the significant attenuated backscattering coefficient (Fig. 5b) for $532 \mathrm{~nm}$ between 06:00 09:00 LST was about 2 3 times that of the high depolarization period on 18 March. Vertical distribution of enhanced attenuated backscattering coefficient was mainly below $1500 \mathrm{~m}$. It was earlier deduced from hourly data that air pollutants was the major component of the first peak of hourly $\mathrm{PM}_{10}$ concentration at 08:00 LST at Wanli station.

In order to identify the aerosol compositions presumed above, the time series of water-soluble ions $\mathrm{Ca}^{2+}, \mathrm{SO}_{4}^{2-}$, and $\mathrm{NO}_{3}^{-}$in $\mathrm{PM}_{2.5}\left(\mathrm{PM}_{10}\right.$ not available in this study) that were monitored by In-situ IC in northern Taiwan are shown in Fig. 5c. The water-soluble ion $\mathrm{Ca}^{2+}$ is generally considered a good indicator of mineral dust while ions $\mathrm{SO}_{4}^{2-}$ and $\mathrm{NO}_{3}^{-}$are mainly from anthropogenic sources. As with the earlier analysis on 17 March, local pollution dominated before frontal passage, ions $\mathrm{SO}_{4}^{2-}$ and $\mathrm{NO}_{3}^{-}$peaked during daytime but no significant $\mathrm{Ca}^{2+}$ concentration. After frontal passage, the concentration of $\mathrm{SO}_{4}^{2-}$ peaked at 07:00 LST which is about 2-3 h prior to the peak of $\mathrm{Ca}^{2+}$ concentration on 18 March. Apparently, air pollutants are the major contributors of $\mathrm{PM}_{10}$ before 08:00 LST, which is consistent with hourly monitored results for ground station (Wanli) and mountain station (Yangming). Concurrently, results of Lidar and Insitu IC show that the transport of air pollutants is prior to the dust aerosol after the frontal passage on 18 March 2005.

The same sequence observed from composition analysis, Lidar and ground stations suggest that northerly flow not only carried dust, but also anthropogenic pollutants to Taiwan for this episode. Air pollutants and dust are not always transported together to Taiwan, for example this case. Apparently, the transport of dust or air pollutants is strongly associated with the boundary structure and transport paths. Unfortunately, currently available data are based on station only without any indications of transport processes. Therefore numerical study obviously plays an irreplaceable role for understanding the transport mechanism of dust or air pollutants to Taiwan.

\subsection{Simulation results and discussion}

Figure 6a shows the simulated spatial distribution of surface dust concentration at 00:00 UTC on 18 March 2005. Concentrations of dust between $100 \sim 150 \mu \mathrm{g} / \mathrm{m}^{3}$ are located from south Japan to northern Taiwan. Surface weather report 

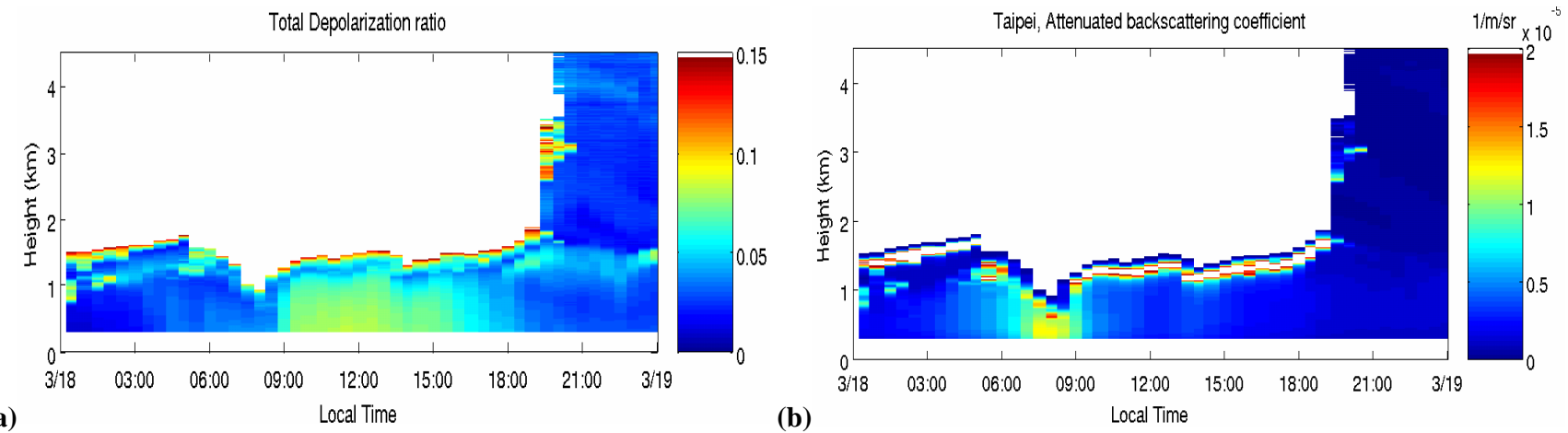

(a)

(b)

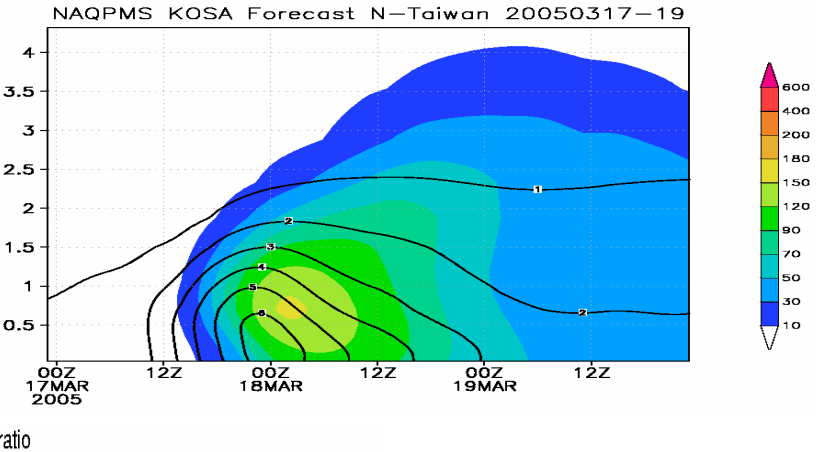

(c)

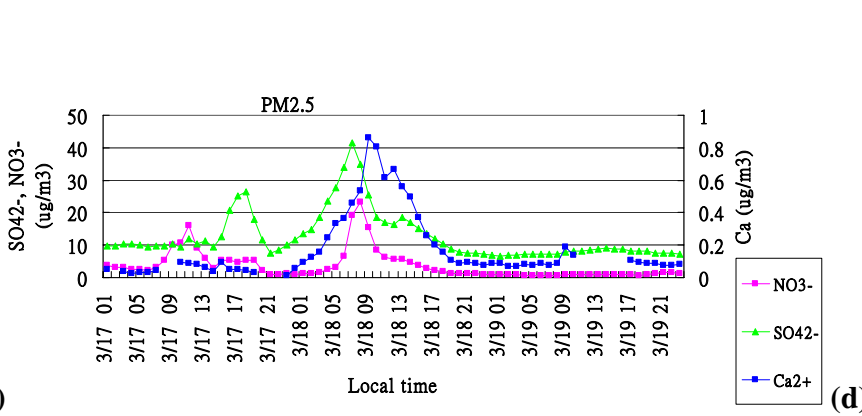

Total Depolarization ratio

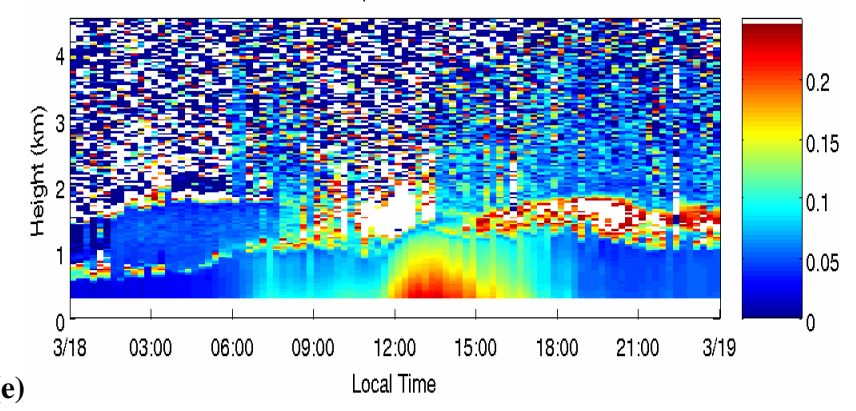

Fig. 5. (a) Time series of depolarization ratio of Lidar observed in northern Taiwan on 18 March 2005. (b) Time series of attenuated backscattering coefficient of Lidar observed in northern Taiwan on 18 March 2005. (c) Time series of hourly soluble ions for $\mathrm{Ca}^{2+}, \mathrm{SO}_{4}^{2-}$ and $\mathrm{NO}_{3}^{-}$in $\mathrm{PM}_{2.5}$ during 17 March 19 March 2005. (d) Simulated vertical profiles of dust concentration (shaded, unit: $\mu \mathrm{g} / \mathrm{m}^{3}$ ) and $\mathrm{SO}_{2}$ (contour, unit: ppb) over northern Taiwan from 00:00 UTC 17 March to 24:00 UTC 19 March 2005. (e) Results of time series of depolarization ratio at Miyakojima Lidar on 18 March 2005.

(Fig. 4b) shows that on 18 March 2005 dust was observed from southern Japan to the islands Amami and Okinawa which are located northeast of Taiwan. Tracing back the trajectory of the dust paths, the spatial distribution of a remarkable simulation of dust concentration (Fig. 6b) are in agreement with the surface weather report (Fig. 4a) in the dust source regions around Inner-Mongolia at 00:00 UTC on 16 March 2005. Simulation results of temporal and spatial distribution of Asian dust demonstrated that the air pocket carrying dust via long-range transport was dominated by a high pressure system following the cold front and formed a band-shaped transport to Taiwan (Chen et al., 2004).

Figure $5 d$ shows the time series of vertical profile of the model predicted over northern Taiwan. The long-range trans- port of dust concentration is mainly below $1.5 \mathrm{~km}$ and peaked nearly $150 \sim 180 \mu \mathrm{gm}^{-3}$ at altitude of about $500 \sim 1000 \mathrm{~m}$ in northern Taiwan from 00:00 UTC (08:00 LST) to 04:00 UTC (12:00 LST) on 18 March. For $\mathrm{SO}_{2}$, it peaked about $6 \sim 8 \mathrm{ppb}$ along with the continental outflow in the morning and prior to the peak of dust concentration. These simulation results agree well with the finding of the high resolution of In-situ IC, i.e. Asian dust and air pollutants are not coincidently transported by the same air masses. Compared to Lidar results (Figs. 5a and b) over northern Taiwan, simulation dust and $\mathrm{SO}_{2}$ distributions both are consistent with the characterization of depolarization ratio and attenuated backscattering coefficient in the vertical distribution. However, compared to the background station's monitoring results in northern 
NAQPMS KOSA Forecast OOZ18MAR2005

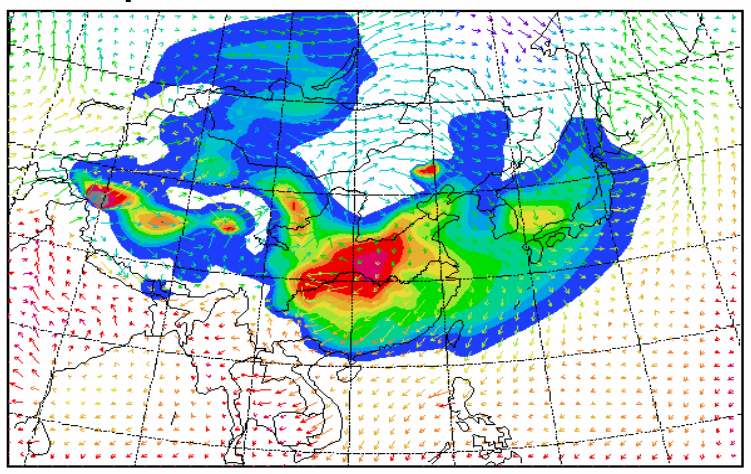

(a)

$\overrightarrow{20}$

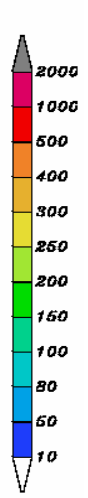

(b)
NAQPMS KOSA Forecast DOZ16MAR2005

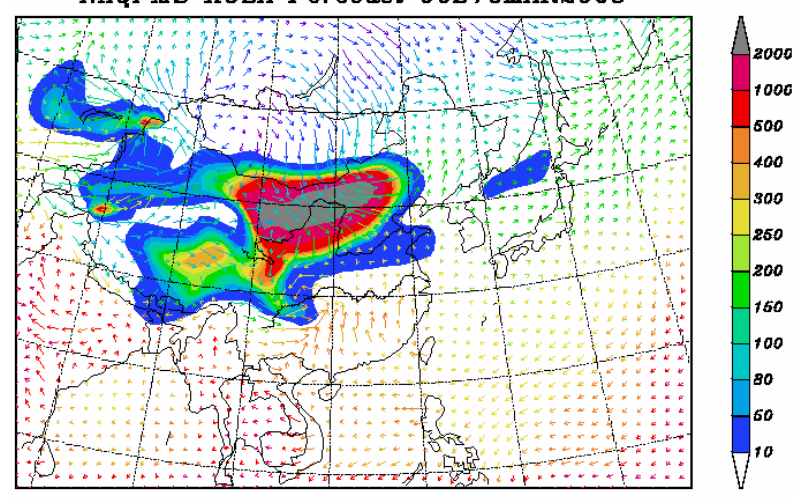

$\overrightarrow{20}$

Fig. 6. Simulated distribution of ground level dust concentration and wind field at (a) 00:00 UTC (08:00 LST) 18 March 2005, (b) 00:00 UTC (08:00 LST) 16 March 2005.

Taiwan (Fig. 2a), numerical results of air pollutants seem underestimate. It is due to Taiwan's emissions are excluded in this numerical study. In addition, emissions inventory might also one of the important reasons as for the emissions in this study are based on the result of the emission inventory in year 2000 by Street et al. (2003), i.e. it could be underestimated of the emission apply to our case in 2005 .

The substantial consistent between observation and model results are also shown at other Lidar site over Miyakojima (125.3 E, 24.7 N) (Fig. 1). Miyakojima is located on an island off north-eastern Taiwan and the air masses are from the similar sources area (Figs. 3a and c) on the episode day. Figure 5e shows the time series of Lidar observation at Miyakojima. The significant depolarization ratio is below $1.5 \mathrm{~km}$ on 18 March at Miyakojima has a similar temporal and vertical distribution but stronger than the result of RCEC/ASNTU Lidar (Fig. 5a). In theory, Miyakojima is quite close to Taiwan; it is expected to have the same level depolarization ratio. However, local emission is significant in northern Taiwan (RCEC/ASNTU Lidar located in downtown) while Miyakojima's local emission can be ignored almost. Therefore, the result of total depolarization ratio in Miyakojima is more evident than that of Taiwan. The time series of simulation longrange transport dust over Miyakojima (not shown) also resemble to northern Taiwan (Fig. 5d) due to their close location. It is apparent that our model results provide important messages for this issue. Figures $7 \mathrm{a}-\mathrm{d}$ show the vertical cross section along the path of the altitude of the $1 \mathrm{~km}$ trajectory that is displayed in Fig. 3a. Taiwan is located at position of "g" in Figs. 7a-d. It is important to note that not only the significant concentrations of dust aerosols, but also air pollutants are transported below the altitude of $1.5 \mathrm{~km}$ before reaching Taiwan (Figs. 7a-d). As mentioned earlier, the atmospheric condition is stable and dry caused by a strong subsidence of the cold high for this episode. A strong subsidence such as this can inhibit the air masses by admixing those transported in the lower boundary. When the air masses passed over East China sea, the boundary layer subsequently developed (Figs. 7b, c and d). This is probably a result of a boundary layer over the East China Sea upwind of Taiwan, which is known for turbulence mixing because of the cold winter monsoon winds over the relatively warm Kuroshio Current. Revisiting the trajectory path (Fig. 3a) at 00:00 UTC on 17 March, nearly all air parcels are located over coastal industrial areas. The dust aerosols have nearly reached the mainland coastal area while a high $\mathrm{SO}_{2}$ concentration is between the mainland coast and Taiwan (Fig. 7a). In the other words, air pollutants transported to Taiwan are prior to dust air masses before they admix properly. A significant concentration of $\mathrm{SO}_{2}$ is continually emitted over the industrial areas of China. Air pollutants are pushed by the dust air masses in the stable atmospheric conditions of the boundary layer as they pass by the major pollutant emission areas of China (Figs. 7a and b). Simulation results also demonstrated that the long-range transport of air pollutants to Taiwan is prior to dust for this case.

Since major paths came from the continent and no evident rainfall occurred (not shown) at stations Yangming and Wanli, the effect of the wet deposition might have weakened before reaching northern Taiwan on 18 March. Furthermore, vertical mixing between dust aerosol and major coastal air pollutant masses are indistinctive due to stable weather conditions and air masses mostly traveled over continental. Therefore, the high $\mathrm{SO}_{2}$ concentration (peaked nearly $14 \mathrm{ppb}$ ) via long-range transport can be observed over Taiwan after wet deposition of the front and the turbulence mixing of cold winter monsoon winds over the relatively warm Kuroshio current. The above processes might have been the major reasons that significant concentrations of air pollutants could be transported for long distances prior to dust transport to Taiwan for this episode. 
(a)
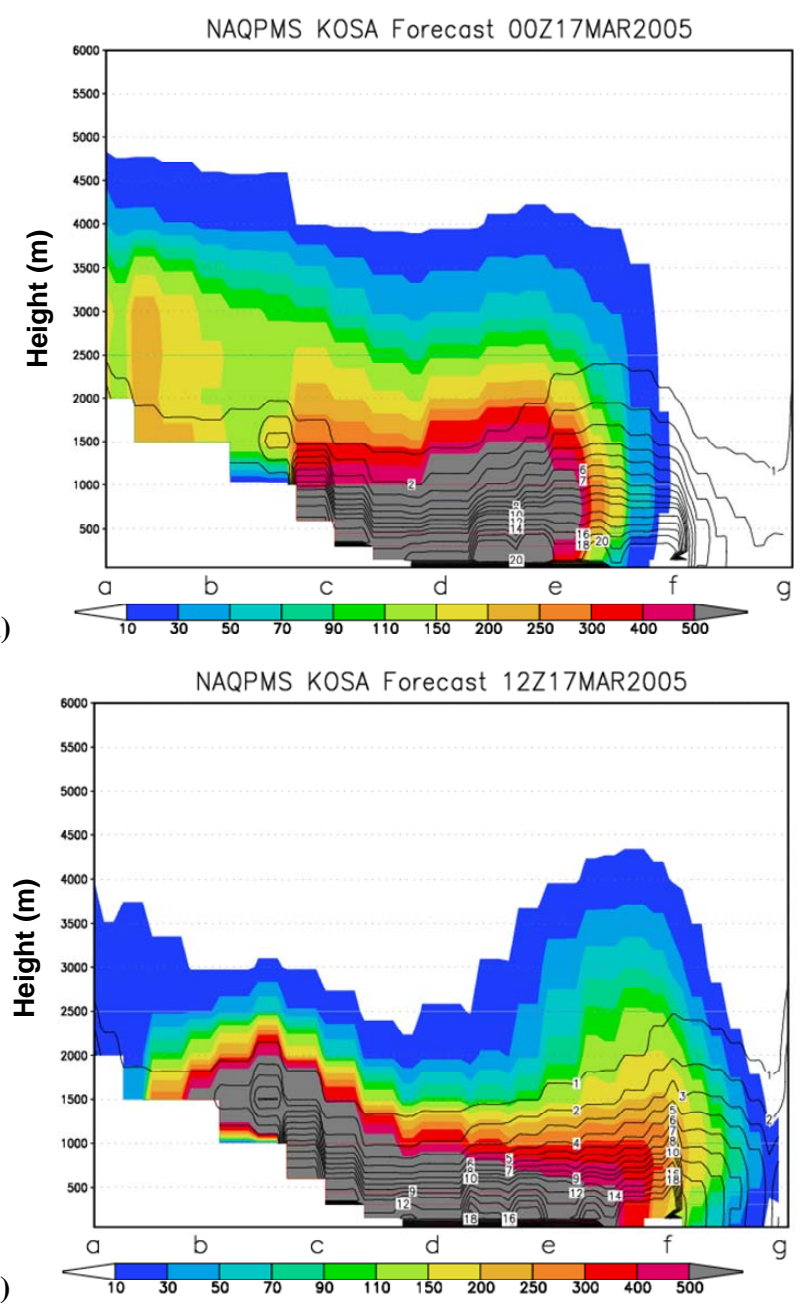

(b)
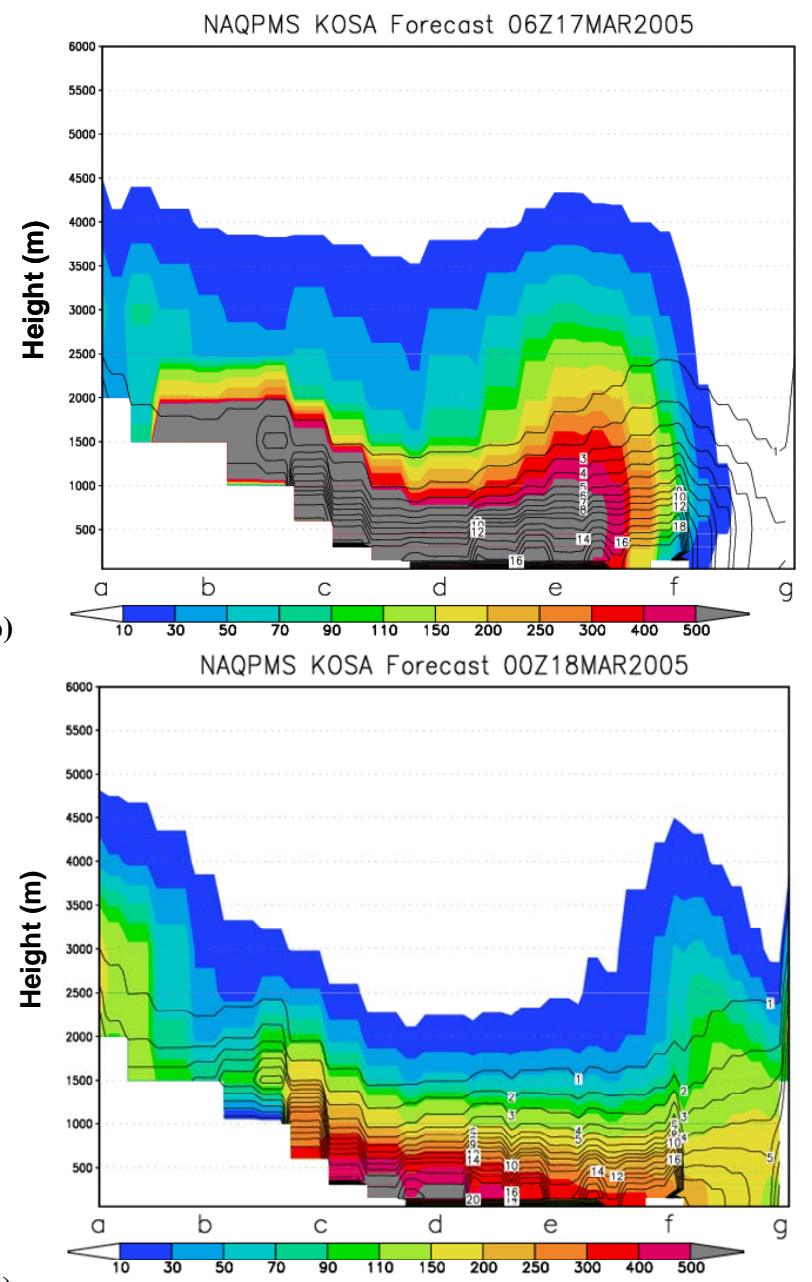

Fig. 7. Simulation results of temporal variations of dust (shaded) and $\mathrm{SO}_{2}$ concentrations (contour lines) of the vertical profile along the path of the altitude of 1000 m in Fig. 3a at (a) 00:00 UTC 17 March 2005 (b) 06:00 UTC 17 March 2005 (c) 12:00 UTC 17 March 2005 (d) 00:00 UTC 18 March 2005. The letters a to $\mathrm{g}$ in $\mathrm{x}$-axis are represented the geographic locations in Fig. 3a.

The observed different composition could be significantly influenced by the transport paths and different vertical mixing processes (Zhou et al., 1990; Matsumoto et al., 2003; Arimoto et al., 2004; Lin et al., 2004). This paper provides the fundamental information to understand what controls the composition of Asian outflow to Taiwan, especially in the low latitude region. Except for this case that shows disagreement in transport between mineral dust and air pollutants, we noted that dust aerosol (mineral particles) arriving over northern Taiwan together with air pollutants also frequently occurred. Therefore, more cases need to be studies to make precise deductions regarding the vertical mixing and transport processes of various types of aerosols to Taiwan.

\section{Summary}

During late winter and spring, high mineral dust concentrations have frequently been observed over East Asia. Along with the long-range transport of Asian mineral dust, anthropogenic air pollutants are occasionally carried by the prevailing winter monsoon.

Data from a background coastal station and mountain station by TEPA showed an episode in which a frontal passage was accompanied by a substantial mass of air pollutants on 18 March 2005. Drastically elevated concentrations of $\mathrm{PM}_{10}, \mathrm{CO}$ and $\mathrm{SO}_{2}$ along with the strong northeasterly were observed over background Wanli station, with peaks of about $170 \mu \mathrm{gm}^{-3}, 1.0 \mathrm{ppm}$ and $14 \mathrm{ppb}$, respectively. Monitoring by RCEC/ASNTU Lidar showed that significant aerosol depolarization ratio occurred below $1.5 \mathrm{~km}$ between 09:00 LST and 18:00 LST on 18 March 2005. 
Meanwhile, the significant attenuated backscattering coefficient for $532 \mathrm{~nm}$ was mainly below $500 \mathrm{~m}$ and about $2 \sim 3 \mathrm{~h}$ earlier than significant depolarization. Continuous measurement of hourly soluble ions demonstrated that air pollutants were the major contributors of $\mathrm{PM}_{10}$ before 08:00 LST while $\mathrm{Ca}^{2+}$ peaked nearly two hours later. Results from TEPA ground stations, RCEC/ASNTU Lidar, and continually Insitu IC consistently showed that the transport of air pollutants was prior to the dust aerosol after the frontal passage for this case.

Results from NAQPMS air quality model suggests that the predicted time series of Asian dust distribution agree excellent with the observation of Lidars that were measured in northern Taiwan and Miyakojima. Overall concentration of air pollutants is underestimated by simulation compared to that of ground stations over northern Taiwan. This is probably due to the emissions input in this study are based on the early inventory (Street et al., 2003) in year 2000 while our study case is in 2005. In addition, local emissions were excluded in this study; it might also be one of the reasons for this concern. Under the stable and dry atmospheric conditions, air pollutants transported to Taiwan are prior to dust also predicted by the model. As dust and air pollutants are from different sources and are transported in dry and stable weather conditions to Taiwan the phenomena of split air parcels for air pollutants and Asian dust transported to Taiwan are strongly associated with the transport paths, and stable and dry atmospheric boundary conditions.

Acknowledgements. We would like to thank the Environmental Protection Administration, Taiwan, ROC for providing the ground station data. The authors gratefully acknowledge the NOAA Air Resources Laboratory (ARL) for the provision of the HYSPLIT transport and dispersion model and READY website (http://www.arl.noaa.gov/ready.html) used in this publication. We thank X. Dong (Sino-Japan Friendship Center for Environmental Protection), J. Zhou (Anhui Institute of Optics and Fine Mechanics), C. H. Lee (Kyung Hee University), S. C. Yoon (Seoul National University), A. Shimizu and I. Matsui (National Institute for Environmental Studies) for their contributions in the Lidar observation. This research was supported by NSC grants, NSC95-2111-M-001-008, and NSC94-2111-M-001-003. This work also partly supported by Key Project of Chinese Academy of Sciences (KZCX2-YW-205), Natural Science Foundation of China (40305018) and Chinese Ministry of Science and Technology (2005CB422205).

Edited by: M. G. Lawrence

\section{References}

Arimoto, R., Zhang, X. Y., Huebert, B. J., et al.: Chemical composition of atmospheric aerosols from Zhenbeitai, China, and Gosan, South Korea, during ACE-Asia, J. Geophys. Res., 109, D19S04, doi:10.1029/2003JD004323, 2004.
Arimoto, R., Duce, R. A., Savoie, D. L., et al.: Relationships among aerosol constituents from Asia and the North Pacific during PEM-West A., J. Geophys. Res., 101, 2011-2023, 1996.

Chang, S.-Y., Fan, G.-C., Chou, C. C.-K., and Chen, W.-N.: Source identifications of $\mathrm{PM}_{10}$ aerosols depending on hourly measurements of soluble components characterization among different events in Taipei Basin during spring season of 2004, Chemosphere, 65, 792-801, 2006.

Chen, J. P., Wang, Z., Young, C.-Y., Tsai, F., Tsai, I.-C., Wang, G.J., Shieh, W.-C., Lin, H. W. Huang, J.-Y., and Lu, M.-J.: Simulation of Asian yellow dust incursion over Taiwan for the spring of 2002 and 2003, Terr. Atmos. Oceanic Sci., 15(5), 949-981, 2004.

Chun, Y. S., Boo, K. O., Kim, K., Park, S. U., and Lee, M.: Synopsis, Transport, and physical characteristics of Asian dust in Korea, J. Geophys. Res., 106, 18 461-18 469, 2001.

Draxler, R. R. and Hess, G. D.: An overview of the Hysplit-4 modeling system for trajectories, dispersion, deposition, Aust. Meteorol. Mag., 47, 295-308, 1998.

Duce, R. A., Unni, C. K., Ray, B. J., Prospero, J. M., and Merrill, J. T.: Long-range atmospheric transport of soil dust from Asia to the tropical North Pacific: Temporal variability, Science, 209, 1522-1524, 1980.

Gao, W., Wei, W., and Liu, M.: Analysis on the regional characteristics of sand-dust aerosol over Tarim Basin, Arid Land Geography, 25(2), 165-169, 2002.

Grell, G. A., Dudhia, J., and Stauffer, D. R.: A description of the Fifth-Generation Penn State/NCAR Mesoscale Model (MM5), Tech. Note NCAR/TN-398+STR, 122 pp, Natl. Cent. for Atmos. Res., Boulder, Colo., 1995.

Huebert, B. J., Bates, T., Russell, P. B., et al.: An overview of ACEAsia: Strategies for quantifying the relationships between Asian aerosols and their climatic impacts, ACE-Asia special issue A, J. Geophys. Res., 108(D23), 8633, doi:10.1029/2003JD003550, 2003.

Husar R. B., Tratt, D. M., Schichtel, B. A., et al.: The Asian dust events of April 1998, J. Geophys. Res., 106(D16), $18317-$ 18330, 2001.

Intergovernmental Panel on Climate Change: Climate Change 2001 - Impacts Adaptation and Vulnerability, Cambridge Univ. Press, New York, 2001.

Jaffe, D. A., Mahura, A., Kelley, J., Atkins, J., Novelli, P. C., and Merrill, J.: Impact of Asian emissions on the remote North Pacific atmostphere: Interpretation of $\mathrm{CO}$ data from Shemya, Guam, Midway, and Mauna Loa, J. Geophys. Res., 102, $28627-$ $28636,1997$.

Li, X., Maring, H., Savoie, D., Voss, K., and Prospero, J. M.: Dominance of mineral dust in aerosol light-scattering in the North Atlantic trade wind, Nature, 380, 416-419, 1996.

Lin, C.-Y., Liu, S. C., Chou, C. C.-K., Liu, T. H., Lee, C.-T., Yuan, C.-S., Shiu, C.-J., and Young, C.-Y.: Long-Range Transport of Asian Dust and Air Pollutants to Taiwan, Terr. Atmos. Oceanic Sci., 15(5), 759-784, 2004.

Lin, C.-Y., Liu, S. C., Chou, C. C.-K., Huang, S.-J., Liu, C.-M., Kuo, C.-H., and Young, C.-Y.: Long-range transport of aerosols and their impact on the air quality of Taiwan, Atmos. Environ., 39, 6066-6067, 2005.

Lin, C.-Y., Wang, Z., Chou, C. C.-K., Chang, C.-C., and Liu, S.-C.: A numerical study of an autumn high ozone 
episode over southwestern Taiwan, Atmos. Environ., in press, doi:10.1016/j.atmosenv.2006.12.050, 2007.

Matsumoto, K., Uyama, Y., Hayano, T., Tanimoto, H., Uno, I., and Uematsu, M.: Chemical properties and outflow patterns of anthropogenic and dust paticles on Rishiri Island during the Asian Pacific Regional Aerosol Characterization Experiment (ACE-Asia), J. Geophys. Res., 108(D23), 8666, doi:10.1029/2003JD003426, 2003.

Murayama, T., Sugimoto, N., Uno, I., et al.: Ground-based network observation of Asian dust eveint of April 1998 in east Asia, J. Geophys. Res., 106, 18345-18359, 2001.

Nakajima, T., Sekiguchi, M., Takemura, T., et al.: Significance of direct and indirect radiative forcings of aerosols in the East China Sea region, J. Geophys. Res., 108(D23), 8658, doi:10.1029/2002JD003261, 2003.

Prospero, J. M., Savoie, D. L., and Arimoto, R. A.: Long-term record of nss-sulfate and nitrate in aerosols on Midway Island, 1981-2000: Evidence of increased (now decreasing?) anthropogenic emissions from Asia, J. Geophys. Res., 108(D1), 4019, doi:10.1029/2001JD001524, 2003.

Prospero, J. M. and Savoie, D. L.: Effect of continental sources of nitrate concentrations over the Pacific Ocean, Nature, 339, 687689, 1989.

Satake, S., Uno, I., Takemura, T., et al.: Characteristics of Asian aerosol transport simulated with a regional-scale chemical transport model during the ACE-Asia observation, J. Geophys. Res., 109, D19S22, doi:10.1029/2003JD003997.

Seinfeld, J. H., Carmichael, G. R., Arimoto, R., et al.: ACE-ASIA regional climate and Atmospheric chemical effects of Asian dust and pollution, Bull. Amer. Meteorol. Soc., 85, 367-380, 2004.

Shaw, G. E.: Transport of Asian desert aerosol to Hawaiian Islands, J. Appl. Meteorol., 19, 1254-1259, 1980.

Sokolik, I. N. and Toon, O. B.: Direct radiative forcing by anthropogenic airborne mineral aerosols, Nature, 381, 681-683, 1996.

Streets, D. G., Bond, T. C., Carmichael, G. R., Fernandes, S. D., Fu, Q., He, D., Klimont, Z., Nelson, S. M., Tsai, N. Y., Wang, M. Q., Woo, J. H., and Yarber, K. F.: An inventory of gaseous and primary aerosol emissions in Asia in the year 2000, J. Geophys. Res., 108(D21), 8809, doi:10.1029/2002JD003093, 2003.
Takemural, T., Uno, I., Nakajima, T., Higurashi, A., and Sano, I.: Modeling study of long-range transport of Asian dust and anthropogenic aerosols from East Asia, Geophys, Res. Lett., 29, 2158, doi:10.1029/2002GL016251, 2002.

Uematsu, M., Duce, R. A., Prospero, J. M., Chen, L., Merrill, J. T., and McDonald, R. L.: Transport of mineral aerosol from Asia over the North Pacific Ocean, J. Geophys. Res., 88, 5343-5352, 1983.

Uematsu, M., Yoshikawa, A., Muraki, H., Arao, K., and Uno, I.: Transport of mineral and anthropogenic aerosols during a Kosa event over East Asia, J. Geophys. Res., 107(D7), 4059, doi:10.1029/2001JD000333, 2002.

Uno, I., Amano, H., Emori, S., Kinoshita, K., Matsui, I., and Sugimoto, N.: Trans-Pacific yellow sand transport observed in April 1998: A numerical simulation, J. Geophys. Res., 106, $18331-$ 18334, 2001.

Uno, I., Carmichael, G. R., Street, D. G., et al.: Regional chemical weather forecasting system CFORS: Model description and analysis of surface observations at Japanese island stations during the ACE-Asia experiment, J. Geophys. Res., 108(D23), 8668, doi:10.1029/2002JD002845, 2003.

Wang, Z., Ueda, H., and Huang, M.: A deflation module for use in modeling long-range transport of yellow sand over East Asia, J. Geophys. Res., 105, 26 947-26 960, 2000.

Wang, Z., Akimoto, H., and Uno, I.: Neutralization of soil aerosol and its impact on the distribution of acid rain over East Asia: Observation and model results, J. Geophys. Res., 107(D19), 4389, doi:10.1029/2001JD001040, 2002.

Zhang, X. Y., Gong, S. L., Shen, Z. X., et al.: Characterization of soil dust aerosol in China and its transport and distribution during 2001 ACE-Asia:1. Network observations, J. Geophys. Res., 108(D9), 4261, doi:10.1029/2002JD002632, 2003.

Zhao, T. L., Gong, S. L., Zhang, X. Y., and McKendry, I. G.: Modeled size-segregated wet and dry deposition budgets of soil dust aerosol during ACE-Asia 2001: Implications for trans-Pacific transport, J. Geophys. Res., 108(D23), 8665, doi:10.1029/2002JD003363,2003.

Zhou, M.-Y., Yang, S.-J., Parungo, F. P., and Harris, J. M.: Chemistry of marine aerosols over the western Pacific Ocean, J. Geophys. Res., 95, 1779-1787, 1990. 